\title{
Analisis Keluaran Berkas Elektron Pesawat Terapi LINAC Tipe Varian CX 6264 di Rumah Sakit Universitas Andalas
}

\author{
Mona Vadila*, Dian Milvita \\ Laboratorium Fisika Nuklir, Jurusan Fisika \\ Fakultas Matematka dan Ilmu Pengetahuan Alam Universitas Andalas \\ Kampus UNAND Limau Manis, Padang, 25163, Indonesia \\ *monavadila9@gmail.com
}

\begin{abstract}
ABSTRAK
Telah dilakukan penelitian tentang analisis keluaran berkas elektron pesawat terapi linear acceleration (LINAC) pada fantom air. Analisis ini bertujuan untuk mengetahui kondisi pesawat terapi LINAC selama digunakan dengan mengacu pada nilai 1 cGy sama dengan 1 MU. Penelitian dilakukan dengan cara menganalisis muatan yang ditangkap oleh detektor ionisasi chamber dengan faktor koreksi suhu, tekanan, efek polaritas dan rekombinasi ion. Penelitian dilakukan dengan variasi energi $4 \mathrm{MeV}, 6 \mathrm{MeV}$, $9 \mathrm{MeV}, 12 \mathrm{MeV}, 15 \mathrm{MeV}$ dan $18 \mathrm{MeV}$ dengan teknik penyinaran Source to Surface Distance (SSD) 100 $\mathrm{cm}$. Ukuran luas lapangan penyinaran yang digunakan adalah $(10 \mathrm{x} 10) \mathrm{cm}$. Hasil analisis menunjukkan bahwa pada berkas elektron energi $4 \mathrm{MeV}, 6 \mathrm{MeV}, 9 \mathrm{MeV}, 12 \mathrm{MeV}, 15 \mathrm{MeV}$ dan $18 \mathrm{MeV}$ didapatkan nilai keluaran per 1 MU sebesar 0,981 cGy, 1,005 cGy, 1,019 cGy, 1,013 cGy, 1,017 cGy dan 1,007 cGy dengan deviasi pengukuran $1,92 \%, 0,54 \%, 1,90 \%, 1,30 \%, 1,73 \%$ dan $0,72 \%$., nilai ini masih berada dalam rentang toleransi pengukuran yaitu $\pm 3 \%$. Dengan demikian, keluaran berkas radiasi elektron pesawat terapi LINAC di Rumah Sakit Universitas Andalas (RS Unand) telah sesuai standar TRS 398 IAEA.
\end{abstract}

Kata kunci: berkas elektron, berkas foton, fantom air, LINAC, RS Unand

\section{ABSTRACT}

The radiotherapy electron beam output linear acceleration (LINAC) on the water phantom has been analysed. The analysis aims to determine the condition of LINAC when it is operated the with reference value of 1 cGy equal to 1 MU obtained from chamber ionization analysis, temperature, pressure, polarity effects and ion recombination. Research was conducted with $6 \mathrm{MV}$ and $10 \mathrm{MV}$ energy variations for photon beam and $4 \mathrm{MeV}, 6 \mathrm{MeV}, 9 \mathrm{MeV}, 12 \mathrm{MeV}, 15 \mathrm{MeV}$ and $18 \mathrm{MeV}$ for electron beam. The size of the radiation field used is $(10 \times 10) \mathrm{cm}$ with radiation technique Source to Surface Distance (SSD) of $100 \mathrm{~cm}$. The result of showed that $4 \mathrm{MeV}, 6 \mathrm{MeV}, 9 \mathrm{MeV}, 12 \mathrm{MeV}, 15 \mathrm{MeV}$ and $18 \mathrm{MeV}$ electron beam obtained output value per $1 \mathrm{MU}$ are $0.981 c G y, 1.005 c G y, 1.019 c G y, 1.013 c G y, 1.017 c G y$ and $1.007 c G y$ with measurement deviation $1.92 \%, 0.54 \%, 1.90 \%, 1.30 \%, 1.73 \%$ and $0.72 \%$ correspondingly. These values are within the measurement tolerance range of $3 \%$. Thus, the radiotherapy electron beam output linear acceleration (LINAC) at Andalas University hospital (RS Unand) has complied with standard TRS 398 IAEA.

Keywords: electron beam, photon beam, water phantom, LINAC, RS Unand

\section{PENDAHULUAN}

Radioterapi merupakan metode pengobatan penyakit-penyakit keganasan seperti kanker dengan menggunakan radiasi pengion (Susworo, 2007). Proses ionisasi sebagai hasil interaksi radiasi pengion dengan sel kanker akan membuat rantai DNA kanker putus sehingga mematikan jaringan tersebut (Williams dan Thwaites, 1993). Dosis radiasi yang diberikan pada sel kanker harus terdistribusi secara merata dan sebisa mungkin minim dosis radiasi yang jatuh di luar lapangan penyinaran. Rentang energi elektron untuk keperluan radioterapi adalah (6-29) $\mathrm{MeV}$ (Khan, 2005).

Linear Accelerator (LINAC) adalah salah satu pesawat teleterapi yang dirancang untuk mempercepat pergerakan elektron secara linier sehingga dapat menghasilkan berkas foton dan elektron (Khan, 2005). Berkas foton biasanya memiliki energi $6 \mathrm{MV}$ dan $10 \mathrm{MV}$, sedangkan berkas elektron memiliki energi $(4,6,9,12,15$ dan 18) MeV. Berkas foton digunakan untuk menyinari kanker yang berada di dalam jaringan tubuh misalnya kanker payudara, kanker servix dan kanker nasofaring, sedangkan berkas elektron biasanya digunakan untuk menyinari kasus kanker kulit (Pratiwi, 2010).

Pengukuran dan perhitungan dosis pada radioterapi harus dilakukan dengan tepat dan sesuai standar pada protokol Technical Report Series (TRS) 398 yang dikeluarkan oleh 
International Atomic Energy Agency (IAEA) pada akhir tahun 2000. TRS 398 adalah suatu kode praktis Internasional untuk dosimetri berdasarkan standar dosis serap air yang dijadikan sebagai pedoman dalam penentuan dosis serap berkas radiasi pesawat terapi eksternal. IAEA merekomendasikan agar dosis yang diberikan pada terapi pasien memiliki ketidakakuratan yang dapat ditoleransi pada jangkauan $\pm 5 \%$, bahkan keluaran radiasinya bisa sampai $\pm 3 \%$. Jika keluaran radiasi yang diperoleh $>3 \%$, maka akan memberikan dampak negatif pada pasien.

Rahayu dkk. (2015) telah melakukan penelitian tentang analisis keluaran berkas radiasi elektron LINAC. Analisis dilakukan dengan variasi energi $6 \mathrm{MeV}, 9 \mathrm{MeV}, 12 \mathrm{MeV}$ dan 15 $\mathrm{MeV}$ menggunakan protokol TRS 398. Hasil penelitian menunjukkan bahwa pada kedalaman maksimum berkas elektron $6 \mathrm{MeV}, 9 \mathrm{MeV}, 12 \mathrm{MeV}$ dan $15 \mathrm{MeV}$ pada luas lapangan (10 x 10) $\mathrm{cm}$ mengalami penyimpangan yang bervariasi namun masih dalam batas toleransi yang ditetapkan yaitu $\pm 3 \%$.

Penelitian tentang analisis keluaran berkas elektron pesawat terapi LINAC perlu dilakukan di RS Unand Padang. Hal ini dikarenakan pesawat terapi LINAC di RS Unand diproduksi pada tahun 2017 dan belum pernah digunakan untuk pengobatan pasien. Sebelum LINAC digunakan, maka perlu dilakukan analisis keluaran berkas radiasi terlebih dahulu agar dosis radiasi yang diterima pasien sesuai dengan yang dibutuhkan dan sesuai dengan asas proteksi radiasi. Analisis dilakukan dengan mengukur keluaran berkas elektron pesawat terapi LINAC (tipe CX 6264) pada energi 4, 6, 9, 12, 15 dan $18 \mathrm{MeV}$ dan membandingkan hasilnya dengan protokol TRS 398 IAEA dimana 1 cGy sama dengan 1 Monitor Unit (MU) dengan batas toleransi $\pm 3 \%$.

\section{METODE}

Penelitian dilakukan di Instalasi Radioterapi RS Unand dan Laboratorium Nuklir Jurusan Fisika Unand. Alat yang digunakan pada penelitian ini adalah pesawat terapi LINAC tipe CX 6264 sebagai sumber untuk menghasilkan berkas elektron, fantom air sebagai pengganti pasien untuk mengukur keluaran berkas elektron, blue phantom digunakan sebagai pengganti pasien pada pengukuran Percentage Depth Dose (PDD). Elektrometer digunakan sebagai pembaca besar muatan yang mengalir pada ion chamber plane parallel. Ion chamber digunakan untuk mengukur keluaran berkas radiasi elektron. Selanjutnya ion chamber reference dan field sebagai detektor dalam pengukuran PDD dan Computer Control Unit (CCU) sebagai pengontrol sekaligus penghubung antara detektor ion chamber reference dan field dengan komputer pembaca pada saat pengukuran PDD.

\subsection{Pengukuran PDD Berkas Elektron}

Pengukuran PDD dilakukan menggunakan blue phantom yang telah berisi aquades. Blue phantom tersebut dihubungkan dengan reference detector dan field detector. Kedua detektor disambungkan ke Computer Control Unit (CCU) yang telah terhubung ke komputer pembaca. Selanjutnya dilakukan penyinaran pada variasi energi $(4,6,9,12,15$ dan 18) MeV. Pengukuran PDD dilakukan untuk menentukan nilai-nilai kedalaman referensi ekuivalen $\left(z_{\text {ref }}\right)$ yang digunakan dalam pengukuran keluaran berkas elektron.

\subsection{Pengukuran Faktor Koreksi}

Penentuan nilai keluaran berkas radiasi elektron pada pesawat terapi LINAC memerlukan beberapa faktor koreksi. Faktor koreksi tersebut antara lain:

1. Faktor tekanan dan temperatur $\left(k_{\mathrm{TP}}\right)$

Pengukuran faktor koreksi ini dilakukan dengan cara mengukur nilai tekanan udara pada saat pengukuran berlangsung $(P)$ dengan tekanan referensi $\left(P_{0}\right)$ sebesar $101,325 \mathrm{kPa}$ dan nilai temperatur rongga chamber $(T)$ dengan temperatur referensi $\left(T_{0}\right)$ sebesar $20^{\circ} \mathrm{C}$. Nilai faktor koreksi $k_{\mathrm{TP}}$ dihitung menggunakan Persamaan (1)

$$
k_{T P}=\frac{273,15+T}{273,15+T_{0}} \frac{P_{0}}{P}
$$


2. Elektrometer $\left(k_{\text {elec }}\right)$

Faktor kalibrasi elektrometer biasanya bernilai 1 yang berarti bahwa chamber dikalibrasi bersamaan dengan elektrometer.

3. Efek polaritas $\left(k_{\mathrm{pol}}\right)$

Pada berkas elektron energi tinggi dilakukan pengukuran pada polaritas positif $\left(M_{+}\right)$, polaritas negatif $\left(M_{\text {. }}\right)$ dan polaritas yang rutin digunakan $(M)$. Nilai efek polaritas $k_{\mathrm{pol}}$ dihitung menggunakan Persamaan (2)

$$
k_{p o l}=\frac{\left|M_{+}\right|\left|M_{-}\right|}{2 M}
$$

4. Rekombinasi ion $\left(k_{\mathrm{s}}\right)$

Faktor rekombinasi ion ditentukan dengan mengukur jumlah muatan pada tegangan yang biasa digunakan $\left(M_{1}\right)$ beserta tegangan referensinya $\left(M_{2}\right)$. Faktor rekombinasi ion juga dipengaruhi oleh nilai koefisien kuadratik $\left(a_{0}, a_{1}\right.$ dan $\left.a_{2}\right)$. Nilai rekombinasi ion $k_{\mathrm{s}}$ dihitung menggunakan Persamaan (3)

$$
k_{s}=a_{0}+a_{1}\left(\frac{M_{1}}{M_{2}}\right)+a_{2}\left(\frac{M_{1}}{M_{2}}\right)^{2}
$$

5. Faktor koreksi respon detektor ionisasi $\left(k_{\mathrm{Q} . \mathrm{Q} 0}\right)$

Faktor koreksi respon detektor ionisasi adalah perbedaan antara respon detektor ionisasi dalam kualitas berkas yang digunakan sebagai kalibrasi detektor terhadap kualitas berkas elektron. Faktor koreksi ini dapat dilihat pada Tabel 7.III TRS 398 sebagai fungsi dari kualitas berkas $\mathrm{R}_{50}$.

\subsection{Pengukuran Keluaran Berkas Radiasi Elektron}

Pengukuran keluaran berkas radiasi elektron pada pesawat terapi LINAC dilakukan menggunakan detektor ion chamber plane parallel pada fantom air yang diatur dengan Source to Surface Distance (SSD) $100 \mathrm{~cm}$. Pengukuran dilakukan pada luas lapangan penyinaran dan perangkat aplikator $(10 \times 10) \mathrm{cm}$ dengan variasi energi $(4,6,9,12,15$ dan 18) $\mathrm{MeV}$. Penyinaran dilakukan sebanyak lima kali pada tegangan $+300 \mathrm{~V},-300 \mathrm{~V}$ dan $+100 \mathrm{~V}$. Nilai keluaran berkas elektron pada kedalaman referensi $\left(z_{\text {ref }}\right)$ dihitung menggunakan Persamaan (4) dan pada kedalaman maksimum $\left(z_{\max }\right)$ dihitung menggunakan Persamaan (5)

$$
\begin{array}{r}
D_{W, Q}=M_{Q} . . N_{D, W, Q 0} \cdot k_{q . q 0} \\
D_{W, Q(\max )}=100 D_{W, Q} / P D D_{(\text {zref })}
\end{array}
$$

$D_{\mathrm{w}, \mathrm{Q}}$ adalah dosis serap pada kedalaman $z_{\text {ref }}(\mathrm{cGy} / \mathrm{MU}), M_{\mathrm{Q}}$ adalah dosimeter pembaca (nC/MU), $N_{\text {D,W,Q0 }}$ adalah koefisien kalibrasi dalam hal dosis serap air pada kualitas referensi Q0. Nilai $N_{\mathrm{D}, \mathrm{w}, \mathrm{Q} 0}$ pada ion chamber plane parallel adalah 8,663 x $107 \mathrm{~Gy} / \mathrm{C} . P D D\left(z_{\text {ref }}\right)$ adalah nilai persentase untuk pengukuran di kedalaman $z_{\text {ref }}(\%)$ dan $D_{\mathrm{w}, \mathrm{Q}}(\max )$ adalah dosis serap pada kedalaman maksimum (cGy/MU).

\section{HASIL DAN DISKUSI}

\subsection{Nilai Pengukuran PDD pada Kedalaman Referensi Ekuivalen}

Hasil pengukuran nilai PDD pada berkas elektron ditunjukkan pada Tabel 1. Hasil pengukuran menunjukkan nilai PDD pada masing-masing kedalaman referensi berbeda-beda. Nilai PDD yang diperoleh berbanding lurus terhadap kedalaman referensi. Semakin besar nilai kedalaman referensi suatu berkas elektron, maka semakin besar nilai PDD yang diperoleh. Sebaliknya, semakin kecil nilai kedalaman referensi suatu berkas elektron, maka semakin kecil nilai PDD yang diperoleh (Khan, 2005). 
Tabel 1 Nilai PDD elektron pada kedalaman referensi ekuivalen $\left(z_{\text {ref }}\right)$

\begin{tabular}{cccc}
\hline No & Energi $(\mathbf{M e V})$ & $z_{\text {ref }}\left(\mathbf{g} / \mathbf{c m}^{2}\right)$ & PDD $(\%)$ \\
\hline 1 & 4 & 0,728 & 96,56 \\
2 & 6 & 1,358 & 96,91 \\
3 & 9 & 2,066 & 96,85 \\
4 & 12 & 2,912 & 98,65 \\
5 & 15 & 3,686 & 98,76 \\
6 & 18 & 4,412 & 98,92 \\
\hline
\end{tabular}

\subsection{Nilai Pengukuran Faktor-faktor Koreksi Berkas Elektron}

Nilai faktor-faktor koreksi digunakan sebagai parameter untuk menentukan keluaran berkas elektron pada kedalaman referensi ekuivalen dengan variasi energi $(4,6,9,12,15$ dan 18) $\mathrm{MeV}$. Akan tetapi, tidak semua nilai faktor koreksi terdapat pada TRS 398 IAEA. Faktor koreksi yang tidak terdapat pada TRS 398 IAEA yaitu efek polaritas $\left(k_{\mathrm{pol}}\right)$ dan rekombinasi ion $\left(k_{\mathrm{s}}\right)$. Oleh karena itu, dilakukan pengukuran jumlah muatan berkas elektron rata-rata terlebih dahulu untuk menentukan nilai faktor koreksi efek polaritas dan rekombinasi ion. Nilai faktor koreksi efek polaritas menggunakan nilai muatan pada tegangan $+300 \mathrm{~V}$ dan $-300 \mathrm{~V}$, sedangkan nilai faktor koreksi rekombinasi ion menggunakan nilai muatan pada tegangan $+300 \mathrm{~V}$ dan $+100 \mathrm{~V}$. Data pengukuran jumlah muatan rata-rata berkas elektron ditunjukkan pada Tabel 2. Hasil pengukuran faktor-faktor koreksi berkas elektron ditunjukkan pada Tabel 3.

Tabel 2 Data pengukuran jumlah muatan untuk berkas elektron pada tekanan $994 \mathrm{hPa}$, temperatur $19^{\circ} \mathrm{C}$ dan kelembaban $50 \%$

\begin{tabular}{cccc}
\hline No & $\begin{array}{c}\text { Energi } \\
(\mathbf{M e V})\end{array}$ & $\begin{array}{c}\mathbf{V} \\
(\mathbf{V o l t})\end{array}$ & $\mathbf{M}(\mathbf{n C} / \mathbf{1 0 0 M U})$ \\
\hline \multirow{2}{*}{1} & 4 & +300 & 11,22 \\
& & -300 & 11,21 \\
& & +100 & 11,09 \\
2 & \multirow{2}{*}{6} & +300 & 11,78 \\
& & -300 & 11,76 \\
& & +100 & 11,62 \\
3 & 9 & +300 & 12,10 \\
& & -300 & 12,13 \\
& & +100 & 11,98 \\
4 & \multirow{2}{*}{12} & +300 & 12,35 \\
& & -300 & 12,38 \\
& & +100 & 12,21 \\
5 & 15 & +300 & 12,54 \\
& & -300 & 12,56 \\
& & +100 & 12,41 \\
6 & \multirow{2}{*}{18} & +300 & 12,59 \\
& & -300 & 12,56 \\
& & +100 & 12,46 \\
\hline
\end{tabular}

Nilai faktor koreksi tekanan, temperatur dan kelembaban $\left(k_{\mathrm{TP}}\right)$ yang telah diperoleh pada setiap energi bernilai sama yaitu 1,016 . Hal ini dikarenakan nilai $k_{T P}$ hanya dipengaruhi oleh parameter tekanan, temperatur dan kelembaban yang ketiganya bernilai konstan dalam penelitian ini. Selanjutnya nilai faktor koreksi efek polaritas $\left(k_{\text {pol }}\right)$ bernilai sama pada energi $(6$, 9, 12, 15 dan 18) $\mathrm{MeV}$ yaitu 0,999 dan berbeda pada energi $4 \mathrm{MeV}$. Hal ini dikarenakan jumlah muatan berkas elektron pada energi $4 \mathrm{MeV}$ jauh lebih kecil dibandingkan energi $(6,9,12,15$ dan 18) $\mathrm{MeV}$, sehingga nilai $k_{\text {pol }}$ pada energi $4 \mathrm{MeV}$ menjadi lebih besar. Selanjutnya nilai faktor rekombinasi ion $\left(k_{\mathrm{s}}\right)$ yang telah diperoleh berbeda pada setiap energi. Hal ini dikarenakan jumlah muatan elektron yang mengalir ke detektor pada setiap energi berbeda. Nilai $k_{s}$ juga dipengaruhi oleh nilai koefisien kuadratik yang dapat dilihat pada Tabel 4.VII TRS 398 IAEA. 
Tabel 3 Nilai faktor-faktor koreksi keluaran berkas elektron

\begin{tabular}{llcccccc}
\hline \multirow{2}{*}{ No } & \multirow{2}{*}{ Faktor } & \multicolumn{7}{c}{ Energi (MeV) } \\
\cline { 3 - 8 } & Koreksi & $\mathbf{4}$ & $\mathbf{6}$ & $\mathbf{9}$ & $\mathbf{1 2}$ & $\mathbf{1 5}$ & $\mathbf{1 8}$ \\
\hline 1 & $k_{\mathrm{TP}}$ & 1,016 & 1,016 & 1,016 & 1,016 & 1,016 & 1,016 \\
2 & $k_{\mathrm{pol}}$ & 1,001 & 0,999 & 0,999 & 0,999 & 0,999 & 0,999 \\
3 & $k_{\mathrm{s}}$ & 1,005 & 1,006 & 1,006 & 1,007 & 1,006 & 1,007 \\
4 & $k_{\text {elec }}$ & 1,000 & 1,000 & 1,000 & 1,000 & 1,000 & 1,000 \\
5 & $k_{\mathrm{q}, \mathrm{qo}}$ & 0,955 & 0,937 & 0,920 & 0,912 & 0,904 & 0,892 \\
6 & $P D D \mathrm{z}_{\text {ref }}$ & 96,56 & 96,91 & 96,85 & 98,65 & 98,76 & 98,92 \\
\hline
\end{tabular}

Semua nilai faktor-faktor koreksi keluaran berkas elektron bernilai $\approx 1$. Hal ini berarti bahwa nilai faktor-faktor koreksi pada penelitian telah sesuai dengan standar yang diterapkan pada TRS 398 IAEA yaitu $\approx 1$.

\subsection{Nilai Pengukuran Keluaran Berkas Elektron}

Hasil pengukuran keluaran berkas elektron pada variasi energi (4, 6, 9, 12, 15 dan 18) $\mathrm{MeV}$ ditunjukkan pada Tabel 4. Nilai kedalaman referensi yang digunakan pada setiap energi berbeda dan dapat dilihat pada Tabel 1. Hasil keluaran berkas elektron yang telah diperoleh pada energi (4, 6, 9, 12, 15 dan 18) $\mathrm{MeV}$ menunjukkan bahwa hasil penelitian ini tidak jauh berbeda dengan hasil penelitian Rahayu (2015). Keluaran berkas elektron pada setiap energi sekitar $1 \mathrm{cGy} / \mathrm{MU}$. Nilai minimal deviasi keluaran berkas elektron diperoleh pada energi $6 \mathrm{MeV}$ $(0,54 \%)$ dan nilai maksimal pada energi $4 \mathrm{MeV}(1,92 \%)$. Akan tetapi, secara keseluruhan nilai deviasi keluaran berkas elektron pada setiap energi masih berada dalam batas toleransi TRS 398 IAEA yaitu $\pm 3 \%$.

Tabel 4 Penentuan keluaran berkas elektron

\begin{tabular}{ccccc}
\hline No & $\begin{array}{c}\text { Energi } \\
(\mathbf{M e V})\end{array}$ & $\begin{array}{c}\text { Penentuan Keluaran } \\
\text { pada } \boldsymbol{z}_{\text {ref }}(\mathbf{c G y} / \mathbf{M U})\end{array}$ & $\begin{array}{c}\text { Penentuan } \\
\text { Keluaran pada } \\
\boldsymbol{z}_{\max }(\mathbf{c G y} / \mathbf{M U})\end{array}$ & $\begin{array}{c}\text { Deviasi Keluaran } \\
\text { pada } \boldsymbol{z}_{\max } \text { terhadap } \\
\mathbf{M U}(\boldsymbol{\%})\end{array}$ \\
\hline 1 & 4 & 0,947 & 0,981 & 1,92 \\
2 & 6 & 0,974 & 1,005 & 0,54 \\
3 & 9 & 0,987 & 1,019 & 1,90 \\
4 & 12 & 0,999 & 1,013 & 1,30 \\
5 & 15 & 1,004 & 1,017 & 1,73 \\
6 & 18 & 0,996 & 1,007 & 0,72 \\
\hline
\end{tabular}

\section{KESIMPULAN}

Hasil penelitian memperlihatkan bahwa keluaran berkas radiasi elektron pesawat terapi LINAC di RS Universitas Andalas telah sesuai dengan standar TRS 398 IAEA. Nilai keluaran berkas elektron yang diperoleh per $1 \mathrm{MU}$ dengan variasi energi $(4,6,9,12,15$ dan 18) $\mathrm{MeV}$ masing-masing adalah $(0,981,1,005,1,019,1,013$ 1,017 dan 1,007) cGy dengan penyimpangan pengukuran $1,92 \%, 0,54 \%, 1,90 \%, 1,30 \%, 1,73 \%$ dan $0,72 \%$. Penyimpangan masing-masing berkas masih dalam batas toleransi TRS 398 IAEA yaitu $\pm 3 \%$.

\section{DAFTAR PUSTAKA}

American Association of Phisicists in Medicine, "Comprehensive QA for Radiation Oncology : Report of AAPM Radiation Therapy Committee Task Group-40", 1994, Medical Physics, New York.

IAEA Safety Report, "Absorbed Dose Determination in External Beam Radiotherapy", 2000, No 398, IAEA Library, Austria.

Khan, M.F., The Physics of Radiation Therapy The 4th edition, (Lippincott Wiliams and Wilkins, New York, 2005), hal. 339.

Pratiwi, R.F, "Analisis Keluaran Berkas Radiasi Foton 10 MV pada Pesawat Teleterapi Linear Accelerator”, Skripsi S1, Universitas Diponegoro, 2010. 
Rahayu, I.I., Nurdin, W.B., dan Samad, B.A., "Analisis Dosis Output Berkas Elektron Pesawat Teleterapi Linear Accelerator (Linac) Tipe Varian HCX 6540 Menggunakan TRS 398”, Skripsi S1, UNHAS, 2015.

Susworo, R., Dasar-Dasar Radioterapi, (UI Press, Jakarta, 2007), hal. 8-10.

Williams, J.R., dan Thwaites, D.I., Radiotherapy Physics in Practice, (Oxford University Press, New York, 1993), hal 2. 